\section{Texto, narrador y lector en Lc 10,25-37}

\author{
HERNANDO BARRIOS TAO ${ }^{* *}$
}

RECIBIDO: 17-04-15 - APROBADO: 06-07-15

Resumen: Exégesis y hermenéutica, comprensión, explicación y aplicación del texto son operaciones que continúan divorciadas en los inicios del siglo XXI. El análisis narrativo se encamina al diálogo texto-lector en el contexto de las racionalidades relacionadas con la literatura, la comunicación y la filosofía del lenguaje. Texto-narrador-lector forman un triángulo inseparable, tanto en la génesis como en la interpretación del texto. El artículo presenta la exégesis narrativa de Lc 10,25-37 a partir de la relación texto-narrador-lector, sujetos con su propio horizonte y con la posibilidad de diálogo entre ellos.

Palabras Clave: Exégesis, hermenéutica, narrativa, texto, lector, narrador, Lucas.

PARA CITAR ESTE ARTÍCULO:

Barrios Tao, Hernando. "Texto, narrador y lector en Lc 10,25-37." Theologica Xaveriana 180 (2015): 327-351. http://dx.doi.org/10.11144/ javeriana.tx65-180.tnllc
Text, Narrator and Reader in Lc 10: 25-37

Aвstract: Exegesis and hermeneutics, understanding, explanation and application of the text are operations that are still divorced at the beginning of the 21st Century. The narrative analysis is headed towards the dialogue text-reader in the context of the rationalities related to literature, communication and philosophy of language. Text-narrator-reader for an inseparable triangle, not in the genesis of the text but also in its interpretation. Thus, this article shows the narrative exegesis of Lc 10:35-37 from the relation text-narrator-reader, considering their particular horizons and the possibility of dialogue between them.

KeY wORDs: Exegesis, hermeneutics, narrative, text, reader, narrator, Luke.

\section{Texto, narrador e leitor em Lc 10,25-37}

Resumo: Exegese e hermenêutica, compreensão, explicaçáo e aplicação do texto são operaçôes que continuam desunidas nos inícios do século XXI. A análise narrativa segue ao diálogo texto-leitor no contexto das racionalidades relacionadas com a literatura, a comunicação e a filosofia da linguagem. Texto-narrador-leitor forma um triângulo inseparável, tanto em gênese como na interpretação do texto. $\mathrm{O}$ artigo apresenta a exegese narrativa de Lc10,25-37 partindo da relação textonarrador-leitor, sujeitos com seu próprio horizonte e com a possibilidade de diálogo entre eles.

Palavras chave: Exegese, hermenêutica, narrativa, texto, leitor, narrador, Lucas.

*Este artículo se deriva del Proyecto de investigación (1-TEO-001) "Metodología patrística e interpretación bíblica hoy”, financiado por la Fundación Universitaria Cervantina San Agustín (Bogotá).

** Doctor en Teología y Magíster en Teología Bíblica. Docente investigador, Facultad de Educación y Humanidades, Universidad Militar Nueva Granada (Bogotá); Fundación Universitaria Cervantina San Agustín (Bogotá).Correo electrónico: hernando.barrios@unimilitar.edu.co; hebata@yahoo.com 


\section{Introducción}

En las últimas décadas, los acercamientos al texto bíblico reciben la influencia de las nuevas racionalidades y de los estudios relacionados con literatura, filosofía del lenguaje, comunicación, semiótica. ${ }^{1}$ Del proceso de formación del texto, privilegio de los métodos histórico-críticos, se ha avanzado hacia las dinámicas de los acercamientos literarios que se orientan a la forma final y, por influjo de la nueva hermenéutica, valoran el papel del lector a la hora de la interpretación del texto. ${ }^{2}$ Sin embargo, los trabajos de unos y otros aún se marcan con el sello de la independencia, parcialidad y hasta de la sospecha.

En la segunda década del siglo XXI no se supera la dicotomía entre labor exegética e interpretación del texto para los lectores contemporáneos. La reducción a la aplicación de unos instrumentos y métodos al texto no se restringe a los estudios histórico-críticos sino que tal ruptura contagió también a quienes realizan acercamientos literarios. Análisis narrativo, retórico, estructuralista, por mencionar algunos, detuvieron su camino en las operaciones literarias y muchos no llegan a la meta de la interpretación actual del texto, hasta el punto de que exégeta llegó a ser sinónimo de filólogo, lingüista, políglota o traductor. Exégesis diacrónica y sincrónica reciben el llamado al paso de la exégesis a la hermenéutica, de la exégesis a la teología ${ }^{3}$, tanto de los ámbitos académicos como de aquellos comunitarios en los cuales se espera el mensaje del texto. ${ }^{4}$

Los métodos sincrónicos se centran en el texto con los elementos y procedimientos propios de estos análisis literarios. De modo particular, el análisis narrativo se presenta como un método centrado en los relatos, los cuales por su misma naturaleza e identidad inducen la reacción de los lectores, y por ende, permiten caminar de la exégesis a la hermenéutica. El paso de la comprensión del texto a la interpretación de su mensaje, tarea completa en la labor exegética, es objeto del análisis narrativo y se fundamenta, entre otros autores, en la propuesta hermenéutica de Ricoeur:

\footnotetext{
${ }^{1}$ Barrios Tao, "Racionalidades emergentes y texto bíblico: hacia unas nuevas sendas en la interpretación", 371-398.

${ }^{2}$ Marguerat, "L'exégèse biblique à l'heure du lecteur", 13; Ska, "L'analisi narrativa", 141-144.

${ }^{3}$ Benedicto XVI, Verbum Domini No 35; Pontificia Comisión Bíblica, La interpretación de la Biblia en la Iglesia, 99-100.

${ }^{4}$ Barrios Tao, "Exégesis patrística y exégesis narrativa. Un aporte a la relación exégesis-hermenéutica", 178-181; Simian-Yofre, Metodologia dell'Antico Testamento, 9-22; De la Potterie, "L'esegesi biblica scienza della fede", 130.
} 
La tarea de la hermenéutica es doble: reconstruir la dinámica interna del texto y restituir la capacidad de la obra para proyectarse al exterior mediante la representación de un mundo habitable. Creo que a la primera tarea corresponden todos los análisis orientados a articular entre sí comprensión y explicación, en el plano de lo que he llamado el "sentido" de la obra.

La exégesis narrativa considera que los relatos bíblicos sobrepasan el sentido pensado por el autor para lectores de un contexto determinado: "Una narración es un mundo-en-palabras que puede ofrecer una nueva perspectiva para comprender el mundo en que los lectores se encuentran viviendo." ${ }^{6}$ De ahí que en el ejercicio hermenéutico, la explicación del texto involucra no solo al lector implícito sino también a los lectores reales que se acercan al texto y en cualquier momento histórico pueden entablar un diálogo con él, a partir de la configuración e intencionalidad de su autor. El objetivo fundamental del análisis narrativo "consiste en comprender cuál es el itinerario que el texto propone al lector" ${ }^{7}$

Texto, narrador, lector son algunas de las categorías que permiten un acercamiento al relato bíblico para adentrarse a un ejercicio exegético que puede desembocar en una hermenéutica del texto que permite explicar y aplicar el texto al contexto del lector contemporáneo. Considerar la particularidad de cada una de estas categorías en una unidad literaria es una tarea difícil porque en su forma final ellas se entrecruzan. Sin embargo, por motivos estructurales del artículo se proponen en apartados diferentes y no se discute que cada una manifiesta la integridad de la unidad literaria.

El artículo de investigación socializa la exégesis sincrónica a la narración contenida en Lc 10,25-37 y se aborda en la interrelación texto-narrador-lector, cada uno de los cuales se considera como un sujeto con su propio horizonte, lo cual no solo permite una verdadera interpelación para los lectores reales sino posibilita el reto del diálogo entre ellos.

\section{Texto: la apertura del diálogo}

La dinámica comprensión-explicación, exégesis-hermenéutica, exige la consideración del sujeto que permite la apertura del diálogo, el texto. Lc 10,25-37 se determina como la unidad literaria a considerar y no presenta problemas notables que induzcan a

\footnotetext{
${ }^{5}$ Ricoeur, "Narratividad, fenomenología y hermenéutica", 205.

${ }^{6}$ Weren, Métodos de exégesis de los evangelios, 105.

${ }^{7} \mathrm{Ska}$, "L’analisi narrative", 146.
} 
dudar del texto y su sentido. ${ }^{8}$ Un gran número de manuscritos realizan una corrección al texto en el verso 30: $\aleph^{2}$ A C ${ }^{2} \mathrm{D} L \mathrm{~L} Q \mathrm{Q}$ Y. Se trata de un claro arreglo al texto mediante la conjunción coordinada de con el fin de conectar y conseguir la unidad de la narración. La lectura seleccionada se sustenta en la versión primera de algunos manuscritos, $\boldsymbol{\aleph}^{*} \mathrm{C}^{*}$, pero son fundamentales por su autoridad tanto el $\mathrm{P}^{75}$ como el uncial B. ${ }^{9}$ Otra variante en esta misma línea de corregir y de completar el texto se encuentra en el verso 32: la expresión [genonenos] kata. ton tópon, se presenta de forma diversa en $\mathrm{P}^{75}$ y $^{45}$, así como en los mayúsculos A y C. En esta variante el análisis se enfoca en el término griego genonenos con el cual se logra una mejor comprensión del texto pero no se cambia su sentido.

\section{Límites y contexto literario de Lc 10, 25-37}

La delimitación del texto no solo permite ubicar el inicio y fin de la unidad literaria sino también ubicar la unidad al interior de una macrounidad y de la entera obra. Los relatos se enmarcan en un comienzo y un final que da sentido a la unidad literaria, lo cual supone para el lector una tarea de delimitación mediante una serie de indicadores o criterios narrativos que el mismo texto propone. Elementos temporales, espacios geográficos, personajes, temáticas, son aspectos que pueden indicar el inicio o fin de una unidad literaria.

Lc 10,25-37 presenta un personaje nuevo que señala el inicio del texto y que entra en escena acompańado por otro personaje conocido por el lector por su nominación en 10,21.23. El nuevo personaje demarca la nueva unidad, por un lado, y, por otro lado, el personaje conocido por el lector señala la conexión con la unidad literaria anterior. El personaje anónimo también señalará el cierre de la unidad cuando desaparece del texto, al ser despedido por Jesús. En el verso 38 se marca la nueva unidad cuando el narrador, en un escenario nuevo, presenta un nuevo personaje: "una mujer llamada Marta".

La temática de la unidad 10,25-37 en torno de asuntos relacionados con prójimo, vida eterna, misericordia, determina novedad en relación con los temas anteriores: $m i$ sión, revelación, bienaventuranza, y separa a su vez con los motivos que se desarrollan en la siguiente unidad: palabra, elección. Sin embargo, no se podría declinar del todo la relación con las unidades anteriores y aquella posterior. Considerar la unidad 10,25-37

\footnotetext{
${ }^{8}$ Metzger, A Textual Commentary on the Greek New Testament. Lc 10.

${ }^{9}$ Para el texto se sigue la versión 27 de Nestle-Aland. La traducción del autor busca la mayor cercanía con el texto, y los términos griegos se utilizan cuando son necesarios para sustentar los planteamientos.
} 
al interior de la parte central del tercer Evangelio, el camino hacia Jerusalén, iniciada en 9,51, causa dificultad, pero ubicarla en la secuencia narrativa que inicia en 10,1 permite enlazar la macrotemática con las unidades que conforman esta secuencia: ¿cómo se determina la unidad de la secuencia narrativa del Capítulo 10 y el puesto de 10,25-37 como parte de la secuencia narrativa abierta en 10,1?

Para explicar el texto, es necesaria la comprensión de su contexto literario. Lucas articula diferentes unidades narrativas a partir de una temática específica y compone sus textos por episodios, con libertad temática y estructural (ver Lc 7; 15; 16; 24):

Lucas utiliza una técnica narrativa muy sencilla: alinea unas historias cortas que forman un todo y que están destinadas a edificar y a conmover. Este procedimiento de composición por episodios, por otro lado, ya se lo habían dictado sus fuentes, aunque él lo perfecciona insertando de vez en cuando breves sumarios que sirven de transición y de pausa para recuperar el aliento. ${ }^{10}$

Lc 9 se construye a partir del texto marcano de la misión y el envío de los discípulos a Israel. La universalidad de la salvación es un tema teológico lucano que debe superar esta misión particular y la secuencia narrativa de Lc 10 es el diseño ideal con la misma temática de misión y envío, ahora de los setenta (y dos), con un alcance que va más allá de las fronteras de Israel y de misioneros delimitados por raza, género o creencia. Las unidades literarias de esta secuencia permiten apreciar la temática unificadora de esta macrounidad: Lc 10,1-20, envío y regreso de los setenta y dos; Lc 10,21-23, anuncio del Evangelio a los sencillos; Lc 10,25-37, el prójimo... más allá de la proximidad; Lc 10,38-42, la mujer... un llamado al discipulado.

El prólogo redaccional lucano $(10,1)$ traza la secuencia temática sobre la misión universal mediante el envío de un grupo más amplio que los Doce: "Después de esto, designó el Señor a otros setenta (y dos), y los envió de dos en dos delante de sí, a todas las ciudades y sitios donde él había de ir" (Lc 10,1). La primera unidad (Lc 10,1-20), refiere el envío que no se particulariza a ciudad alguna (v. 8.10.12), más aún, descarta con una crítica aguda las ciudades de Israel por su negativa a la conversión. Lc 10,21-24 es la segunda unidad literaria en la cual se manifiesta la apertura del mensaje, revelación de "estas cosas", a quienes estén en disposición, sin condición previa de exclusividad o elección, esto es, a los pequeños, a quienes el Padre se ha revelado. La universalidad de la misión se manifiesta en su apertura a los sencillos que se vinculan con el anuncio del Evangelio.

${ }^{10}$ Bovon, El Evangelio según San Lucas. Lc 1,1-9, 31. 
Más allá de la tercera unidad, Lc 10,25-37, la última, Lc 10,38-42, es sugerente, porque la misión universal, configurada en este nuevo grupo simbólico más amplio, supera la dimensión aritmética para entrar en el espectro de la condición. Esta unidad adquiere la forma de invitación a la mujer vinculada con la comunidad lucana (ver Lc 8,1 ), que no ha cruzado la frontera de su labor tradicional en el ambiente judío: se le presenta la parte mejor, "sentarse a escuchar la palabra", asumir la condición de discípula (ver Hch 22,3).

Lc 10,1 marca el inicio de una macrounidad, secuencia temática narrativa, determinada por uno de los aspectos claves en la teología lucana, la universalidad de la salvación y de la misión, reafirmada con el envío de los setenta y dos, más allá de la misión de los Doce, presentado en la secuencia anterior. Aquí el tema fundamental es la misión en clave lucana con características universales. ¿Cómo se articula 10, 25-37 en la temática de la misión universal y el envío, presentes en esta secuencia del Capítulo 10? Es uno de los interrogantes que conducirá el análisis narrativo en los puntos siguientes.

\section{Acciones y diálogos en Lc 10,25-37}

La escasez de verbos de acción caracteriza la unidad literaria 10,25-37, que se dinamiza principalmente por sus diálogos, fundamentales en el relato bíblico, no solo porque a través de ellos se puede lograr el acercamiento a los personajes sino porque en los diálogos se contiene el mensaje del texto. No obstante, es necesario anotar que, en la narrativa bíblica, palabras, diálogos y acciones son categorías incluyentes, unas y otras se pueden identificar.

Los verbos de movimiento expresan acciones, son el motor del relato, conducen el ritmo de los personajes y la dinámica del texto. Por su parte, los verbos que introducen diálogos son fundamentales para visualizar la estructura del texto. ${ }^{11}$ La primera acción puntual, "se levantó" (anesth), complementada con el participio presente (đape razWn), poniéndolo a prueba, se relaciona con la presentación del nuevo personaje: "Cierto maestro de la ley". Este fondo ambienta el diálogo que dominará la primera parte, la cual se cierra con una nueva acción del mismo personaje: un participio presente, "queriendo" (q́́l wn), con un infinitivo aoristo, "justificarse" (d kai w\$ai ). Esta acción también servirá de introducción para la segunda parte del texto $(10,30-35)$.

\footnotetext{
${ }^{11}$ La narración a través del diálogo es una característica de la narrativa bíblica en relación con la estructuración, funciones y mensaje. Alter, L'arte della narrativa biblica, 84ss.; Ska, "L'analisi narrativa", 148; Shimon, El arte de la narrativa en la Biblia, 187ss.
} 
El texto se estructura en dos partes a partir de los diálogos entre los dos personajes. Las dos construcciones verbales de acción anotadas introducen las dos partes de la unidad literaria. El diálogo inicial entre el legista y Jesús fija la primera parte y la pregunta retórica con la cual se finaliza la primera parte señala el inicio de la segunda parte de la unidad:

amesth ekpei razun auton (se levantó tentándolo)

I egun (diciendo)

o' de ė pen proj autron (Y dijo a él)

o’de apokri qej j è (Y habiendo respondido dijo)

ei pen de autw* (Y dijo a él)

o’ de qel un d kai w\$ai èuton (queriendo justificarse)

ė æron proj ton Vhsoun ( dijo a Jesús)

kai . tij eti n nou pl hsi onÈ (¿y quién es mi prójimo?)

甘pol abun o' Whsou' ė

tij toutwn twh tri wh pl hsi on dokè/soi gegonenai tou/eapesontoj

ejj touj I h\$taj Ė(¿Quién de estos tres prójimo te parece llegó a ser..?)

o’de è pen (Y dijo)

è pen de autw/|' 'Vhsoü' (Y dijo a él Jesús)

Considerar el contenido de los diálogos permite apreciar la estructura con mayor claridad:

Maestro, ¿Qué habiendo hecho vida eterna heredaré?

en la Ley ¿Qué ha estado escrito? ¿Qué lees?

Amarás al Señor tu Dios con todo tu corazón y con toda tu alma y con toda tu fuerza y con toda tu mente, y a tu prójimo como a ti mismo.

Rectamente has respondido. Estos has y vivirás.

¿Y quién es mi prójimo? 
Un hombre bajaba desde Jerusalén hacia Jericó y en manos de salteadores cayó, los cuales habiéndolo despojado y golpes habiéndole dado se fueron habiéndolo dejado medio muerto. Y por casualidad cierto sacerdote bajaba por aquel camino y habiéndolo visto pasó por otro lado. Y del mismo modo también un levita [genonenoj] por el lugar habiendo llegado y habiendo visto pasó por otro lado. Pero cierto samaritano estando de viaje vino junto a él y habiéndolo visto se compadeció. Y habiéndose acercado vendó sus heridas derramando aceite y vino, y habiéndolo montado sobre la propia cabalgadura lo condujo hacia una posada y cuidó de él. Y al día siguiente habiendo sacado dio dos denarios al posadero y dijo: "Cuida de él y lo que gastes yo al regresar te lo pagaré."

¿Quién de estos tres, prójimo te parece llegó a ser del que cayó en manos de los salteadores?

el que hizo misericordia con él.

camina y tu haz del mismo modo

En la estructura se resaltan los dos diálogos centrales. Mientras que la construcción del primer diálogo sigue la dinámica pregunta-contenido-reacción, en el segundo diálogo se aprecia la inclusión que se enmarca en dos preguntas: pregunta-contenidopregunta. El contenido temático central que desarrolla toda la unidad responde a la pregunta "¿qué habiendo hecho, vida eterna heredaré?"

El contenido del primer diálogo no solo se relaciona con el del segundo discurso sino que su conexión se puede marcar con el sello de la novedad y el contraste. El contenido del primero no refiere directamente algún pasaje de la Torah sino que la respuesta se construye con base en más de un texto (ver Dt 6,5; Lv 19,18; 18,5) y recoge la concepción y actitud tradicional para con el prójimo ${ }^{12}$, y a su vez se determina como el motivo para introducir el segundo discurso, parte central del texto. Una vez que el narrador manifiesta la actitud del legista, se plantea la pregunta que condensa la temática del texto, en el marco de la secuencia narrativa de Lc 10: “¿Quién es mi prójimo?” El pleonasmo en la introducción a la respuesta no solo llama la atención sobre el personaje ahora nominado sino también sobre sus palabras mismas: "Dijo a Jesús [...] habiendo respondido, dijo Jesús.” La respuesta en forma de narración $(10,30 \mathrm{~b}-35)$ no solo es la respuesta a un interrogante sino que allí se ubica el mensaje

${ }^{12}$ El término $\mathrm{pl} \mathrm{hsion} \mathrm{es} \mathrm{un} \mathrm{adverbio} \mathrm{sustantivado} \mathrm{que,} \mathrm{en} \mathrm{griego,} \mathrm{generalmente,} \mathrm{requiere} \mathrm{del} \mathrm{artículo.}$ En los dos usos del texto vv. 29.36, sin artículo, el término "predicativo" es sugerente. Ver a Blass y Debrunner, Grammatica del greco del Nuovo Testamento \$266; y a Balz y Schneider, Diccionario exegético del Nuevo Testamento II, 1006. 
central de la unidad. Por este motivo, la atención del lector se debe centrar allí, sin descuidar la totalidad de la unidad.

\section{Estructura del relato}

Los relatos se componen de cuadros que son microestructuras que permiten al narrador ubicar personajes, señalar diferentes escenarios o presentar diversas situaciones. Lc 10,25-37 se dinamiza más por diálogos que por cambios de escenario, personajes o situaciones. Un solo escenario en el que interactúan sus dos personajes, el maestro de la ley y Jesús:

\section{Introducción primera parte}

Y he aquí un cierto maestro de la Ley se levantó tentándolo,

\section{Cuadro I}

diciendo: Maestro, ¿Qué habiendo hecho vida eterna heredaré?

Y dijo a él: en la ley ¿Qué ha estado escrito? ¿Qué lees?

\section{Cuadro II}

Y habiendo respondido dijo: Amarás al Señor tu Dios...

Y dijo a él: Rectamente has respondido. Esto haz y vivirás.

\section{Introducción segunda parte}

Y queriendo justificarse

\section{Cuadro III}

dijo a Jesús: ¿Y quién es mi prójimo?

Habiendo respondido Jesús dijo: Un hombre bajaba desde Jerusalén hacia Jericó...

\section{Cuadro IV}

¿Quién de estos tres, prójimo te parece llegó a ser del que cayó en manos de los salteadores? Y él dijo: el que hizo misericordia con él.

\section{Epílogo}

Y le dijo Jesús: camina y tu haz del mismo modo

En los diálogos que conforman los cuadros se aprecia el binomio preguntarespuesta que dinamiza el texto. A cada pregunta se sigue linealmente una respuesta. El atento lector no puede desviar su mirada del Cuadro III cuya respuesta no solo es extensa sino que adquiere forma de relato. 


\section{Narrador: la dirección del diálogo}

\section{Intervenciones y orientaciones del narrador}

El texto analizado en el numeral anterior no se aísla de la consideración del narrador; al contrario, lo supone. De ahí que, por metodología y estructura del artículo, el narrador se considera en este nuevo aparte, aunque su pluma se haya dejado sentir en la estructura del texto con sus diálogos y acciones. El narrador se define como la voz que construye la historia y teje la trama, o como el artista que modela los elementos del relato: trama, personajes, tiempo, espacio. El narrador es la instancia que cuenta la historia y configura el material en un relato articulado; por tanto, él no solo se posiciona respecto del texto sino que también conduce al lector en su trasegar por el texto.

El vínculo estrecho entre texto y narrador supera la consideración de la voz como un ente descriptivo e indiferente para llegar a una instancia que algunas veces interviene por medio de comentarios, preguntas o juicios. Más aún, en ocasiones no solo interviene sino que a veces entra en el relato, se deja ver en el texto y lo hace metiéndose en él como narrador narrado de forma homodiegética, como narrador presente en la historia contada, y lo logra mediante la voz que relata en primera persona plural o singular. ${ }^{13}$ No obstante, la preferencia de la voz narrativa en el relato bíblico se caracteriza porque cuenta en tercera persona, sin entrometerse en el texto.

En términos generales Lc 10,25-37 evidencia un narrador que relata en tercera persona. La apertura del texto presenta un narrador ausente de la historia, es heterodiegético (vv. 25-29), pero que no se limita a contar sino que interviene en el relato, narrador intradiegético, en dos momentos. En la primera intervención, v. 25 , mediante la valoración de la actuación del legista, se inserta en sus pensamientos e intenciones: "poniéndolo a prueba" (ekpeirazwn). ${ }^{14}$ El participio presente indica una acción en el presente y no pasa desapercibida para los lectores atentos. La otra actitud interior del personaje, v. 29, nueva intervención, se construye también con

\footnotetext{
${ }^{13}$ La forma heterodiegética es cuando el narrador se ausenta del relato. El narrador que interviene en la historia contada busca que el lector participe en las experiencias de los personajes (instancia intradiegética). El narrador extradiegético, de cara al lector, pretende que éste ejercite su labor de intérprete. Ver a Marguerat y Bourquin, Cómo leer los relatos bíblicos, 41-50; Bal, Teoría de la narrativa, 126; Garrido, El texto narrativo, 43.

${ }^{14}$ La determinación de esta actitud como una intervención del narrador para caracterizar el personaje y llamar la atención del lector se fundamenta al confrontar el texto con las unidades de Marcos, posible fuente de Lucas: Mc 12,28-31 y 10,17. Allí dos elementos denotan el paralelo con el texto lucano: un escriba relacionado con el primer mandamiento y un joven con la misma pregunta acerca de las acciones para heredar la vida eterna. Intenciones o juicios de estos personajes están ausentes del relato marcano.
} 
un participio presente ahora complementado con un infinitivo aoristo: "queriendo justificarse" (qal wn d kai w\$ai).

La segunda parte de la unidad, vv. 30-37, presenta un narrador en aparente actitud de relatar la historia, instancia extradiegética. Una mirada atenta del lector lo descubre dibujado al interior del relato, homodiegético, a través de uno de los personajes. La dinámica en la presentación del personaje fundamenta la presencia del narrador en el relato. En el verso 25 el título de "maestro" determina el personaje a quien se le dirige una pregunta; en el verso 29, el personaje es nominado y se le dirige una nueva pregunta: "dijo a Jesús"; por último, el verso 30 no solo trae de nuevo el nombre del personaje, sino que asume su voz para continuar la narración: "habiendo respondido Jesús dijo". El narrador, ahora encarnado en la voz del personaje Jesús, relata una nueva historia.

La dinámica del personaje nominado no culmina cuando inicia la nueva historia sino que su presencia continúa ahora al interior del relato que cuenta. El lente del lector se detiene en la figura de uno de los personajes del relato central de la unidad literaria. En el verso 33 aparece en escena un innominado e indeterminado "samaritano" con unas actitudes conocidas por el atento lector: "Pero cierto samaritano estando de viaje (de camino) (tij odaumn hłọn) vino junto a él y habiéndolo visto se compadeció (i dun espl agcni soh)." Dos elementos literarios sugerentes en boca del narrador e indispensables como balizas de lectura. ${ }^{15}$

El participio presente (odaumn) es una acción reconocida por el lector en el contexto del tercer Evangelio, en este punto de la obra, relacionada directamente con el personaje Jesús, quien narra el relato. Esta acción verbal, caminar o ir de viaje, no solo se utilizó por el narrador en el inicio del camino de Jesús hacia Jerusalén (ver Lc 9,52 ss.), sino es un motivo literario que configura la obra lucana. El segundo motivo literario se relaciona con los sentimientos del samaritano frente a la situación del hombre en el camino, no desconocidos por el lector lucano como tampoco para el narrador, Jesús.

Tres capítulos antes, Lc 7,13, el narrador ha delineado la imagen de Jesús en su encuentro con la mujer viuda, cuyo hijo único ha muerto con esta misma actitud: "Habiéndola visto, el Señor, se compadeció" (i dwn authn o’kuri oj æpl agcri sqh). El modo verbal determina una acción puntual, aoristo pasivo: espl agcni soh. El

\footnotetext{
${ }^{15}$ Señales con las cuales el narrador dota el texto para orientar al lector en su interpretación (Marguerat y Bourquin, Cómo leer los relatos bíblicos, 209).
} 
participio aoristo ingresivo ${ }^{16}$ conduce una acción de misericordia con un resultado inmediato. En el Capítulo 7 el fruto es el retorno a la vida del hijo de la viuda. En 10,33, la actitud del samaritano frente al hombre que ha caído en manos de los salteadores es la misma de Jesús, con unas posteriores acciones puntuales en favor del hombre medio muerto. En este punto, las indicaciones literarias logran identificar a Jesús narrador con el samaritano. Esta inserción del narrador narrado, Jesús, en el relato, orienta la atención del lector hacia las acciones puntuales que realiza, y busca su identificación con ellas. Jesús, como los lectores lucanos, son caminantes (ver Lc 24,13-35). Este narrador narrado cuenta la historia pero no permanece externo a ella sino se deja ver en las actitudes del personaje principal (homodiegético).

\section{Tramas en Lc 10,25-37}

La trama es el tejido en el cual el narrador ubica los elementos del relato, acciones, personajes, espacio, tiempo:

El análisis narrativo nos hace caer en la cuenta de que la construcción de una intriga (trama), el dispositivo de una red de personajes, la gestión de la temporalidad y la semantización del espacio son tan indicativos de la intención teológica como una formulación doctrinal o una confesión de fe. ${ }^{17}$

\section{Trama de revelación - Trama de acción: dos partes en Lc 10,25-37}

La presentación del texto 10,25-37 a partir de la estructura quinaria ${ }^{18}$ permite apreciar que no se presenta un solo nudo o problema en el relato sino que el texto continúa más allá:

\section{Situación inicial}

Y he aquí un cierto maestro de la ley se levantó

\section{Nudo}

tentándolo, diciendo: Maestro, ¿Qué habiendo hecho vida eterna heredaré?

\footnotetext{
${ }^{16}$ El aoristo ingresivo pone de relieve el punto inicial de la acción, lo cual supone actos sucesivos “ingresados” por la acción inicial (Blass y Debrunner, Grammatica del greco del Nuovo Testamento $\$ 318,1$ ).

${ }^{17}$ Marguerat, Wenin y Escaffre, En torno a los relatos biblicos, 22.

${ }^{18}$ Este modelo estructural que se ha "impuesto como canónico" descompone el texto en cinco momentos: situación inicial, nudo, acción transformadora, desenlace, situación final (Marguerat y Bourquin, Cómo leer los relatos bíblicos, 71).
} 


\section{Acción transformadora}

Y dijo a él: en la ley ¿Qué ha estado escrito? ¿Qué lees?

Y habiendo respondido dijo: Amarás al Señor tu Dios...

\section{Desenlace}

Y dijo a él: Rectamente has respondido.

\section{Situación final}

Esto haz y vivirás

\section{Situación inicial}

y queriendo justificarse

Nudo

dijo a Jesús: ¿Y quién es mi prójimo?

\section{Acción transformadora}

Habiendo respondido Jesús dijo: Un hombre bajaba desde Jerusalén hacia Jericó...

\section{Desenlace}

¿Quién de estos tres, prójimo te parece llegó a ser del que cayó en manos de los salteadores?

Y él dijo: el que hizo misericordia con él.

\section{Situación final}

Y le dijo Jesús: camina y tú haz del mismo modo

Al interior de la unidad se presentan dos nudos correspondientes con dos preguntas dirigidas a los lectores implícitos: “¿Qué habiendo hecho vida eterna heredaré?”, “¡y quién es mi prójimo?”. A los dos nudos corresponden dos acciones transformadoras con sus respectivos desenlaces. Las dos resoluciones desarrollan el contenido en forma de respuesta a las preguntas problemas. La primera resolución corresponde con la concepción tradicional de los lectores prefigurados en el anónimo "maestro de la ley", y expone la obediencia al amor a Dios y al prójimo, de acuerdo con su comprensión del primer Testamento. La segunda solución, en contraste, además de presentar la novedad de la concepción y vivencia de la experiencia de ser prójimo, anuncia la nueva misión en forma de invitación a "llegar a ser prójimo" gracias a la empatía con el protagonista del microrrelato.

Las dos acciones transformadoras resuelven las problemáticas y configuran una respuesta clara a la dialéctica nudo-desenlace. De manera particular, el nudopregunta problema de la segunda trama, "quién es mi prójimo", no solo se soluciona 
con su respectiva acción transformadora, sino que en su respectivo desenlace es corregida por la nueva pregunta retórica planteada: "Quién [...] prójimo, llegó a ser" (pl hsi on doké/ soi gegonenai ). Las dos situaciones finales corresponden con dos mandatos relacionados con dos misiones para obrar y vivir. Dos modos de obrar que contrastan la experiencia de los lectores: la vivencia tradicional se contrapone con la novedad de la misión universal, desarrollada en toda la secuencia narrativa de Lc 10 . El microrrelato contenido en la acción transformadora de la segunda trama presenta su propia estructura a partir de los cuadros allí contenidos:

\section{Situación inicial}

Un hombre bajaba desde Jerusalén hacia Jericó

\section{Nudo}

y en manos de salteadores cayó, los cuales habiéndolo despojado y golpes habiéndole dado se fueron habiéndolo dejado medio muerto.

\section{Acción transformadora}

Y por casualidad cierto sacerdote bajaba por aquel camino...

Y del mismo modo también un levita...

Pero cierto samaritano estando de viaje vino junto a él y habiéndolo visto se compadeció...

\section{Desenlace}

Y al día siguiente habiendo sacado dio dos denarios al posadero y dijo: "Cuida de él y lo algo gastes yo al regresar te lo pagaré."

La acción transformadora presenta tres personajes mediante los cuales el narrador busca solucionar el nudo. El último personaje, gráfica y literariamente se describe en evidente contraste con los dos anteriores. El texto se suspende y no presenta situación final relacionada con el personaje que cayó en manos de salteadores, ni con el cumplimiento de las acciones del samaritano, de regresar y pagar lo prometido al posadero. ${ }^{19}$

A las dos partes de la unidad literaria corresponden dos tramas de revelación. En la primera trama se presentan dos nudos relacionados con el conocimiento:

\footnotetext{
${ }^{19}$ Esta técnica denominada suspensión narrativa se presenta cuando el narrador, de manera intencionada, interrumpe el relato y transpone al lector la función hermenéutica (Marguerat y Bourquin, Cómo leer los relatos biblicos, 77; Magness, Sense and Absence. Structure and Suspension in the Ending of Mark's Gospel).
} 
“¿Qué habiendo hecho vida eterna heredaré?” “YY quién es mi prójimo?”. La primera trama propone un nudo relacionado con la actuación para heredar la vida eterna y la resolución se construye con base en lo prescrito por Deuteronomio y Levítico. La segunda trama, provocada por el problema acerca de la definición del prójimo, se resuelve con el microrrelato, que induce el cambio de sentido de la pregunta: "¿quién de estos tres prójimo te parece llegó a ser del que cayó en manos de los salteadores?” El mensaje del narrador corrige la pregunta del lector: no se trata de definir el prójimo sino de cambiar la actitud y "llegar a ser" prójimo. A cada nudo corresponde una invitación práctica para actuar de acuerdo con la respuesta.

$\mathrm{Al}$ interior del microrrelato se desarrolla una nueva trama, ahora de acción o resolución. El nudo del relato se determina por la situación del personaje inicial del texto: traumatismo y peligro de muerte. La dinámica del texto, in crescendo, desarrolla la solución de forma escalonada a través de los personajes: dos personajes iniciales que no solucionan, y el tercero, en contraste con los anteriores, ve y se compadece del hombre herido. El narrador no termina el relato sino lo deja abierto a través de una suspensión en la narración y no ofrece información acerca de la situación final del hombre herido y del que se hizo prójimo. Mientras que el primero permanece en la espera de seguir siendo cuidado, el segundo expresa su disponibilidad a pagar lo que fuese necesario. Parecería que "llegar a ser prójimo" no tiene límites, ni en relación con la actitud de hacerse prójimo, ni en las consecuencias, cuando se "llega a tener" la condición de prójimo.

\section{Temática unificadora: la nueva misión universal de Lc 10}

La articulación de 10,25-37 en la temática de la misión universal y el envío, presentes en la secuencia del Capítulo 10, planteada anteriormente, se responde con la consideración de las dos partes de la unidad literaria. Las dos partes que componen la unidad literaria de 10,25-37 se construyen partir del tema del prójimo, central en el mensaje del texto, por medio de dos preguntas: “QQuién es mi prójimo?” (Lc 10,29) y “¿quién de estos tres llegó a ser prójimo?” (Lc 10,36). Estas dos preguntas se relacionan con la nueva misión universal del lector, temática unificadora de la secuencia de Lc 10. El paso de una pregunta a la otra no es casual, sino se convierte en la temática y mensaje central del texto.

Una vez se presenta la respuesta del legista, la contra-respuesta del maestro Jesús -“en la Ley ¿qué ha estado escrito? ¿Qué lees?”- permite al narrador dejar abierta la posibilidad de preguntar al lector, por medio del legista, acerca de la identidad del prójimo: ¿quién es mi prójimo? Esto, con una intencionalidad sugerente de cambiarle sus concepciones: "Lc 10,36 combina el sentido fundamental espacial-concreto de 
pl hsi oncon el objetivo ético de la manera tradicional de hablar acerca del prójimo: lo importante es 'llegarse' al prójimo a quien hemos visto en situación angustiosa." ${ }^{20} \mathrm{En}$ la secuencia de Lc 10, prójimo y misión son categorías articuladas bajo la condición de la universalidad. El narrador propone al lector un cambio en su concepción tradicional moldeada por Levítico y Deuteronomio ${ }^{21}$, y le propone otra con dimensiones universales que superan familia, raza y etnia. Los setenta y dos, llamados en el prólogo de Lc 10, entre los cuales se incluye el lector lucano, reciben la invitación de superar barreras raciales, nacionales y vecinales que enmarcan su concepción, para llegar a ser prójimo de quien lo necesite, cualquiera sea su condición.

\section{Personajes o el mensaje del narrador}

Los personajes permiten hablar al narrador y no solo dinamizan la trama sino que ellos retocan y ornamentan el tejido donde se ubican los demás elementos del relato. Analizar los personajes exige remitirse a la estructura del texto en sus dos partes determinadas por aquellos. Legista y Jesús estructuran la primera parte del relato, mientras que "un hombre", "unos salteadores", "un sacerdote", "un levita”, "un samaritano", "el posadero" estructuran la trama de acción, ubicada al interior del diálogo entre los anteriores personajes. El análisis de los personajes, al interior de cada una de las tramas, se presenta en tres momentos: presentación del personaje, caracterización, relación lector-personaje.

\section{Legista y maestro: dos enseñanzas}

La unidad literaria inicia con la presentación innominada e indeterminada de un nuevo personaje: nomkoj tij $(10,25)$. La caracterización del personaje se logra mediante su oficio y su relación con la Torah, sugerente para la hermenéutica del texto. En los versos posteriores, el legista será presentado por medio del artículo y a través del uso de pronombres personales (ver vv. 27.29.36-37). El carácter indeterminado del personaje lucano es relevante en relación con el texto paralelo de Mt 22,3522 y

\footnotetext{
${ }^{20}$ Balz y Schneider, Diccionario exegético del Nuevo Testamento II, 1008.

${ }^{21}$ Este planteamiento de misión universal cambia el concepto del judío acerca del prójimo, a partir de Lv 19,18. El samaritano se hizo prójimo y esto es novedoso para la identidad de la misión del miembro de los setenta y dos. Así, ahora el sentido no es amar al hermano de raza sino llegar a ser cercano de quien está en necesidad, cualquiera que sea, independientemente de la condición o de la raza.

${ }^{22}$ En la versión 27 de Nestle y Aland, el texto de Mateo propuesto no es seguro cuando realiza la presentación del personaje mediante el término griego nonikg̣. Algunos manuscritos indeterminan mucho más el personaje mediante el uso de la partícula tij (F G H). En la redacción del primer Evangelio, el personaje está en relación con los fariseos.
} 
con el texto marcano en 12,28, supuesta fuente tanto de Lucas como de Mateo. El personaje presentado en Marcos no es un nonikoj sino "uno de los escribas" ( $\dot{\mathrm{a} j} \mathrm{t}$ twh grammatemn). La apuesta lucana por nonikoj en el relato no es casual y requiere un análisis que se desarrollará en relación con el otro personaje, también maestro.

La voz del narrador supera la presentación del personaje hasta arribar a intervenciones que pasan de comentarios a juicios en relación con sus intenciones y motivaciones íntimas. Dos actitudes, mejor, dos sospechosas conductas anteceden sus interrogantes: ekpei razun (v.25) y qd wn d kai w\$ai (v.29). ${ }^{23}$ Plausible resaltar la audacia del narrador, no solo por la denuncia de las motivaciones del personaje sino por la construcción literaria, participio presente, para expresar las actitudes como continuas en el presente y tocar el mundo de los lectores a quienes se dirige el texto. ${ }^{24}$ El anonimato del personaje forma parte de la estrategia del narrador, que va más allá de lograr la identificación con el lector: resaltar y centrar su atención en el personaje nominado, interlocutor del anónimo legista: "Jesús." 25

Con el personaje anónimo e indeterminado, el narrador provoca en el lector algunos sentimientos. El primer impacto del lector frente a la conducta tentadora del legista no puede ser otro sino de sospecha, cuidado y expectativa (v. 25). El contraste entre la conducta del legista y la expresión del término "maestro" en sus labios, suscita sentimientos encontrados en el lector: reverencia con tentación, respeto con ironía y burla. Empatía por la denominación a Jesús como Maestro, pero antipatía por su actitud interior que motiva el interrogante. El narrador juega con sentimientos de empatía, simpatía, antipatía, en el lector frente al personaje anónimo y caracterizado como legista. En relación con la focalización, el narrador ubica al lector en el mismo horizonte de su personaje: tanto lector como legista están en el mismo horizonte de conocimiento acerca de palabras, sentimientos y pensamientos. Esta igualdad de ho-

23 "La indicación de percepciones, deseos e intenciones, emociones, conocimiento y entendimiento cumple un papel definitivo en sus contextos, sea para el diseño de los personajes, para avanzar la trama o para clarificarla." (Shimon, El arte de la narrativa en la Biblia, 26).

${ }^{24}$ El vínculo entre palabras de los personajes en relación con la situación de los lectores implícitos y los propósitos del narrador se puede apreciar en los evangelios (Bennema, "A Theory of Character in the Fourth Gospel with Reference to Ancient and Modern Literature”, 420).

${ }^{25}$ Beck, en su artículo "The Narrative Function of Anonymity in Fourth Gospel Characterization", sustenta diferentes maneras como funciona el anonimato, a través de un análisis en el cuarto Evangelio: (1) Señalar la insignificancia del personaje particular, que permanece discretamente en el fondo del texto narrativo; (2) El nombre es innecesario para la percepción del personaje por parte del lector; (3) Para desviar la atención del lector del personaje innominado al personaje nominado en cuya presencia el personaje innominado se ve; (4) la identificación del lector con el personaje innominado. 
rizontes se logra mediante el grado de focalización interna que conduce al lector a pensamientos e intenciones del personaje (vv. 25.29).

Mediante el uso del pronombre de tercera persona (auton), la voz narrativa presenta un personaje vinculado con el legista y conocido por el lector competente. Las palabras del legista caracterizan este nuevo personaje como "maestro" (d daskal e). ${ }^{26}$ La caracterización de maestro se ubica en confrontación con legista: si se trata de una trama de revelación, las preguntas de un legista las puede responder un maestro. En contraste con el "legista", cuyo nombre no aparece a lo largo del texto, el "maestro" es nominado a partir del verso 29. En el mismo momento en el que la denominación legista desaparece, la caracterización de maestro tampoco se refiere más; ahora se personifica. La centralidad del texto se orienta hacia una persona específica: Jesús. En el cierre del texto, v. 37, el narrador utiliza pronombres para referirse al personaje anónimo; en contraste, evidencia aún más el nombre Jesús cuando presenta la exhortación final: "camina y tu haz del mismo modo".

La conducción de los diálogos, la dinámica en su transformación y la autoridad de su voz, en el relato central de la unidad, permiten determinar el protagonismo del maestro Jesús. La magia del narrador para expresar su mensaje se manifiesta con mayor excelencia en la sutileza con la cual su voz pasa al nominado personaje, Jesús, a partir del verso 30. El narrador entra al mundo del relato, instancia homodiegética, con voz precisa e identificada con la del personaje nominado, el cual inicia un relato en tercera persona. Este relato, central en la unidad literaria, abre una trama con unos personajes nuevos, entre los cuales la voz del narrador, identificado con Jesús, tomará forma en las acciones de uno de ellos. El análisis de los personajes inmersos en el relato central aporta nuevos elementos para la hermenéutica del texto.

\section{Una enseñanza nueva: de ¿quién es mi prójimo? a ¿quién llegó a ser prójimo?}

El relato central de la unidad literaria 10,25-37 es la respuesta a la pregunta planteada por el legista: “¿quién es mi prójimo?”. De ahí que la finalidad de la voz del narrador no sea otra sino responder el interrogante, para cuyo propósito cuenta con los personajes, sus acciones y la nimiedad de sus palabras. El microrrelato inicia con la

\footnotetext{
${ }^{26}$ Cuando Lucas presenta y caracteriza a Jesús las denominaciones más utilizadas son los títulos Salvador, Señor, Comandante (evpista,thj) $(5,5 ; 8,24 ; 8,45 ; 9,33 ; 9$, 49; 17,13). La estrategia del narrador está en consonancia con la presentación del personaje anterior: para la interacción con el maestro de la Ley es preciso no un comandante sino un maestro. La fuente marcana $(12,28)$ no refiere apelativo alguno para Jesús, mientras que el texto de Mateo sí refiere el personaje como maestro $(22,36)$.
} 
presentación indeterminada y anónima de un personaje: "cierto hombre" (anqrupoj tij). La caracterización del personaje se agota en su condición masculina, por lo que se trata de un personaje plano con un rol pasivo en el tejido de la trama. Las acciones desarrolladas en torno de él dinamizan el relato, nudo y acción transformadora, se desarrollan gracias a la situación y posterior intervención y cuidado del que es objeto: cae en manos de salteadores, es golpeado, despojado y en condición mortal, objeto de compasión, curado, portado hacia la posada, cuidado. Este personaje figurante, pasivo y anónimo, se convierte en una de las opciones para la respuesta a la pregunta planteada. El lector no solo se identificaría con él sino que podría asumir que la respuesta sobre el prójimo se concretaría en este personaje necesitado.

Un detalle sugerente para el lector lucano que ha seguido el camino de subida de Jesús hacia Jerusalén $(9,51)$ es la ruta del hombre; procede (apo) de Jerusalén y su meta (ej) es Jericó: "bajaba de Jerusalén hacia Jericó" (katebai nen apo. Ver ousal hm ejj Veri cWy. Su procedencia contrasta con el camino de Jesús, pero para la competencia del lector no es extraña esta dirección de la ruta, como tampoco la realidad de su peligrosidad. La mención de este peligroso sendero alerta al lector y le genera sentimientos encontrados en relación con el personaje: ingenuidad o temeridad del hombre, necesidad o rutina del caminante. No será el único personaje que tomará la ruta en esta dirección contraria al camino de Jesús.

Los nuevos personajes se presentan en el texto en relación directa con el hombre anónimo con el cual se abre el relato. Las acciones de los siguientes personajes, unos salteadores o ladrones ( $\mathrm{h} \$$ tai $\zeta$ ), tienen como objeto el hombre anónimo: robar, despojar y golpear. Las acciones caracterizan la denominación con la cual se presenta este colectivo personaje. Cordel, plano, indeterminado, anónimo, caracterizan este personaje colectivo que se presenta en la narración de manera momentánea, cumple su rol y desaparece. Sentimientos de antipatía se despiertan en el lector, no obstante su conocimiento acerca de la peligrosidad del camino. Este personaje colectivo ¿afirmaría la respuesta al interrogante? Ellos no serían el prójimo ¿pero sí colaborarían con la determinación de un prójimo?

El narrador vincula los dos siguientes personajes con el "hombre" anónimo a través de la ruta seguida por los tres: "bajaban por el camino" (v. 31). La presentación anónima y la indeterminación caracterizan los dos personajes, sacerdote y levita: ièrai tij - Leuithi. El perfecto paralelo no solo se logra con su caracterización a través de actitudes similares sino que se refuerza con aspectos literarios: el narrador los iguala mediante el uso del adverbio "igualmente" (oǹi wì) y de la partícula kal', con valor adverbial (“también”) (v. 32). De ahí que lo que se afirme de uno se podrá sustentar del otro. 
En su orden, sacerdote y levita "por casualidad” (kata. sugkurian) bajan por aquel sendero y ven al hombre herido. El lector atento que busca reforzar la respuesta acerca de la identificación del prójimo con el "hombre" anónimo, consideraría que la ayuda a este prójimo no podría tener mejor representatividad que en dos de los mejores exponentes de su tiempo: un sacerdote y un levita, no solo conocedores de la Ley, del amor a Dios y al prójimo, sino cercanos a la experiencia por su contacto con el Templo de Jerusalén de donde proceden. En la misma dirección del hombre (katebai nen) bajan por casualidad las personas indicadas para demostrar lo que significa el amor a un prójimo.

Sin embargo, la actitud de los personajes desconcertaría a unos lectores y tranquilizaría a otros. A los primeros lectores perturbaría que la actitud de los personajes no fuese la ayuda a un prójimo concreto, pero para otros lectores, quizás judíos habitantes del mundo griego lucano, las actitudes tanto del sacerdote y del levita son coherentes con su ser y hacer dentro de la comunidad judía. Para este lector judío, no solo es motivo de tranquilidad sino de alabanza, tanto el espíritu religioso como el cumplimiento de la Ley por parte de los dos personajes. Este lector conoce no solo la peligrosidad de la bajada de Jerusalén hacia Jericó sino también la Ley (ver $\mathrm{Nm}$ 19,13.16; Lv 22,) y aprueba la actitud de pasar por el lado contrario (anti par $€$ c conai ) de donde se encuentra el hombre "medio muerto", por la coherencia de quien sirve en el Templo y su deber de conservar su pureza. El anonimato de los dos personajes permite a estos lectores identificarse con ellos.

La conjunción pospositiva décon sentido adversativo, es el medio literario eficaz utilizado por la voz narrativa, no solo para contraponer los personajes anteriores con el nuevo caminante sino también para cambiar la concepción al legista y a los lectores, y proponer la novedad: "llegar a ser prójimo". La partícula adversativa no solo marca la novedad del personaje, sino también de sus acciones, concepciones y hasta de la pregunta enunciada. El narrador presenta el nuevo personaje bajo la caracterización del anonimato y la indeterminación: "cierto samaritano" (Samarithj tij). A diferencia de todos los anteriores, el samaritano no "baja" (katebai nen), en actitud permanente en el pasado, como lo señala el imperfecto, sino que está "caminando" (odaumn), participio presente. La caracterización fundamental para enfatizar el contraste con los anteriores es la determinación de su procedencia, o si se quiere, de su etnia. La condición de samaritano es clave y motivo literario, no solo al interior del relato sino para la totalidad de la obra lucana. ${ }^{27}$

${ }^{27}$ Algunos samaritanos ocupan lugares privilegiados y de contraste en la obra lucana (ver 9,52; 17,16; Hch 8,25$)$. Esta contraposición entre personajes de cultura y raza judía con los samaritanos se evidencia 
En relación con los anteriores personajes, las acciones del samaritano ocupan el lugar central del relato, contrastan con las realizadas por el sacerdote y el levita, y son extensas, puntuales e inacabadas. La divergencia entre la actitud del samaritano y la de los dos personajes anteriores se determina por sus primeras acciones: "habiendo visto, se compadeció" (kai .i đ@n espl agcni sqh). El pasivo indica una acción cuyo sujeto no es propiamente el personaje, sino que este es "movido a compasión". Frente al lector competente, la actitud del samaritano genera diversas reacciones. Incomprensión por un samaritano conmovido por causa de un hombre herido "procedente" de Jerusalén, por un lado, y confusión por la actitud contraria a lo realizado por el sacerdote y el levita, por otro; pero lo más significativo reside en que, para el lector atento a la lectura de la obra lucana, esta acción puntual no es desconocida. Es el mismo actuar de Jesús con la viuda que había perdido a su hijo único $(\operatorname{Lc} 7,13)$. En la vida del lector, esta acción permanecerá porque de nuevo aparecerá cuando el padre recibe de nuevo en la casa a su hijo perdido (ver Lc 10,33). ${ }^{28}$

El cuestionamiento a los lectores, como al legista, que posiblemente aprobaron la conducta tanto del sacerdote como del levita, traza un nuevo rumbo a la concepción y al interrogante sobre el prójimo. Uno y otros desarrollan empatía con los valores del compasivo personaje, y cambian la búsqueda de un prójimo para llegar a ser prójimo, como se manifiesta en la respuesta del legista: "el que hizo misericordia". La voz del narrador habla mediante las acciones del samaritano y se dirige a los lectores lucanos respecto de la misión universal que sobrepasa la visión de un prójimo propia de la tradición judía (ver Lc 10,27), para llegar a la novedad del mensaje cristiano: "hacerse prójimo" (ver Lc 10,36).

El rol protagónico del samaritano, Jesús narrado, así como la centralidad del relato al interior de la unidad, se sustenta en la extensión y detalle de las acciones del personaje. Las acciones se deben leer a partir del mensaje enviado: llegar a ser prójimo.

en textos lucanos (ver 9,51-56; 17,11-19). Las actitudes de los samaritanos, ordinariamente, además de ser resaltadas, son objeto de mayor aprobación por parte del narrador. Más aún, sus actitudes generan la reprobación de las obradas por los personajes judíos. El antagonismo, mejor la oposición, rivalidad y enemistad histórica entre judíos y samaritanos no es desconocida para el lector lucano. Para el mundo judío, los samaritanos son los "perros" (ver Mc 7,28; Mt 15,27), los históricos usurpadores de las tierras de sus hermanos del norte. Asimismo, a los samaritanos no les han faltado motivos históricos, religiosos y sociales para rechazar y negarse a acoger a sus opresores judíos (ver Lc 9,51-53).

${ }^{28} \mathrm{La}$ sincrisis es el procedimiento literario tomado de la retórica greco-romana y consiste en poner en paralelo la actividad de varios personajes, bien sea para compararlos, o bien sea para marcar la continuidad entre uno y otro. Lucas es "campeón de la sincrisis" (Marguerat y Bourquin, Cómo leer los relatos bíblicos, 210). El estudio de Aletti sobre esta técnica dominante en la obra lucana presenta casos específicos: Juan Bautista-Jesús; Pedro-Pablo (Aletti, Il racconto come teología, 71-102). 
Más allá de buscar, encontrar o definir un prójimo, el samaritano supera lo que cualquier piadoso debería hacer para ayudar a su próximo o semejante. Las acciones puntuales responden a la situación crítica del hombre y se introducen con la acción de acercarse al herido mediante un participio aoristo ingresivo: "habiéndose acercado" (prose qun). Las acciones incoadas con el participio refieren cuidados específicos: vendar las heridas, katechsen desinfectarlas y mitigar el dolor, "derramando aceite y vino". Las acciones continúan mediante la misma construcción, un nuevo participio aoristo ingresivo: "habiéndolo montando" sobre su propia cabalgadura, con otras acciones puntuales, conducir y cuidar. La última acción se prolonga con el pago de los dos denarios, que significan su responsabilidad, la cual no culmina sino que se abre hasta cuando sea necesario. Estas acciones no solo prolongan el cuidado hasta cubrir la necesidad sino que indican la suspensión del relato, con un texto que no conoce límites en la ayuda al necesitado y en la misión universal de llegar a ser prójimo.

\section{A modo de conclusión: nuevos lectores en diálogo con el texto}

La orientación del análisis narrativo no solo se dirige a dialogar con el texto sino a confrontar al lector con el texto. Los lectores implícitos recibieron el mensaje en su contexto y comprendieron la voz del narrador. El nuevo lector, frente al texto, en un nuevo contexto y con características diferentes, se ubica en el círculo texto-narrador para entablar un diálogo desde su horizonte: "Los relatos duermen hasta cuando el lector no viene a despertarlos de su sueño." ${ }^{29}$ De ahí que la construcción de un relato, la disposición de una trama y de acciones, personajes, tiempo y espacio, tienen la finalidad de involucrar al lector en el mundo del relato, mover e incluso cambiar su sistema de valores. Los horizontes del texto y del narrador se encuentran con el de los nuevos lectores. Algunos aspectos significativos que se podrían plantear de y para los lectores se presentan en este aparte. Tales elementos no pretenden cerrar la exégesis del texto sino abrir preguntas y marcar horizontes de interpretación.

En el camino hacia Jerusalén, a los nuevos lectores se les indica una nueva identidad de la misión del seguidor del Maestro. El paso de la concepción determinada de el prójimo a la visión universal de llegar a ser prójimo señala la misión de los nuevos caminantes. El prójimo, aquí, no se determina simplemente como la persona próxima o cercana, ni aquella perteneciente a cierto grupo, creencia, ni aquel semejante por causa de sus valores, nacionalidad e identidad. El prójimo ahora es el caminante, el viajero en el camino de la vida que, incluso pasando por encima de sus creencias, credos,

${ }^{29}$ Ska, "L’analisi narrativa", 139. 
ritos, ideologías, es capaz de ver en su camino cotidiano de discípulo las necesidades de quienes caen en manos de salteadores. El narrador indica a sus lectores que los nuevos caminantes no son aquellos que buscan, optan o seleccionan a quién ayudar, sino que "llegar a ser prójimo" significa ver y detenerse ante la interpelación de la humanidad necesitada, de los seres humanos que en el camino cotidiano requieren ayuda.

Las acciones referidas por la voz narrativa se relacionan con "hacer" y "llegar a ser”: "Hazlo y vivirás” (v. 28). “¿Quién llegó a ser..?” (v. 36). “...ve y haz tu lo mismo” (v. 37). Estos imperativos se convierten en llamado y confrontan a los nuevos lectores. La invitación del narrador es a pasar de doctrinas, creencias y convicciones hacia un actuar coherente con la condición de caminantes y con el seguimiento hacia Jerusalén. Legista, levita y sacerdote podrían tener claras sus convicciones religiosas y cultuales. Los nuevos lectores también podrán tener claridad en sus creencias. Sin embargo, ellas no pueden ser obstáculo para la nueva condición, "llegar a ser prójimo”. El caminante, con una nueva misión universal, escucha la voz para hacer y obrar en consonancia con su ser, que lo conduce a acercarse, ver, sentir y actuar con un corazón semejante al del prójimo, al de quien se hizo prójimo, el que "hizo misericordia". Misericordia, amor, verdad, justicia, no se determinan para los nuevos caminantes como convicciones o creencias religiosas sino como acciones reveladoras de la presencia de Dios en la existencia, lo cual permite superar raza, condición, religión, etc.

"Llegar a ser prójimo" no tiene medida en el contexto universal de la nueva misión de los caminantes. Para los lectores, esta misión supera la imposible relación judío-samaritano y relativiza cualquier norma, rito, deber, moralidad, que sea obstáculo para "hacer misericordia" o ayudar a quien se encuentra en necesidad. La universalidad no solo se considera a partir de la superación de la raza o condición, sino también por la ruptura de los límites que ya no se pueden establecer cuando se trata de ayudar al necesitado. La suspensión narrativa del relato, por un lado, obliga al lector a finalizar el relato en relación con su actuar frente al hombre que continúa en la posada, y por otro, a recibir el mensaje del narrador, de que la ayuda al necesitado no depende de una programación o planeación sino de la necesidad, y de que sus límites tampoco se programan sino que su fin los marca la necesidad misma.

El mundo del lector se puede representar en el mundo del levita, del sacerdote y del legista, centrado en ellos mismos y sus creencias, o en el mundo de Jesús y del samaritano, abierto a las necesidades de los otros y del mundo. La misión universal, con el paso de los Doce a los setenta (y dos), interpela a los nuevos lectores en relación con la salida de los mundos particulares y de los límites para considerar la necesidad de los otros. "Llegar a ser prójimo" implica las actitudes de ver y sentir, de contemplar y dejarse mover por la misericordia; esta condición no es otra sino la 
de tener la capacidad de salir de los propios y particulares mundos para ver, actuar e involucrarse, para observar y a la vez dejarse sensibilizar por la realidad de los otros, que aunque diferentes, por el simple hecho de ser y estar en el mundo invitan a salir de sí mismos y de mundos religiosos y culturales, muchas veces construidos. Tal actitud de los nuevos lectores contrasta con uno de los grandes signos de nuestro tiempo, la insensibilidad. El texto presenta los "rodeos" de unos personajes ante el necesitado, los cuales impiden comprometer la vida, tranquilizan conciencias y evaden afectaciones y responsabilidades.

\section{Bibliografía}

Aletti, Jean-Noël. Il racconto come teologia. Studio narrativo del terzo Vangelo e del Libro degli atti degli Apostoli. Bologna: Edizioni Dehoniane, 2009.

Alter, Robert. L'arte della narrativa biblica. Brescia: Queriniana, 1990.

Bal, Mieke. Teoría de la narrativa. Una introducción a la narratología. Madrid: Cátedra, 1990.

Balz, Horst y Gerhard Schneider. Diccionario exegético del Nuevo Testamento. Vol. I. Salamanca: Sígueme, 1996.

. Diccionario exegético del Nuevo Testamento. Vol. II. Salamanca: Sígueme, 1998.

Blass, Friedrich y Albert Debrunner. Grammatica del greco del Nuovo Testamento. Brescia: Paideia, 1982.

Barrios Tao, Hernando. "Exégesis patrística y exégesis narrativa. Un aporte a la relación exégesis-hermenéutica." Franciscanum 164 (2015): 171-210.

- "Racionalidades emergentes y texto bíblico: hacia unas nuevas sendas en la interpretación.” Theologica Xaveriana 163 (2007): 371-398.

Beck, David. "The Narrative Function of Anonymity in Fourth Gospel Characterization." Semeia 63 (1993): 143-158.

Benedicto XVI. Verbum Domini. Roma: Editrice Vaticana, 2010.

Bennema, Cornelius. "A Theory of Character in the Fourth Gospel with Reference to Ancient and Modern Literature." Interpretation 17 (2009): 375-421.

Bovon, François. El Evangelio según San Lucas. Lc 1,1-9, 50. Salamanca: Sígueme, 1995.

De la Potterie, Ignace. "L'esegesi biblica scienza della fede." En L'esegesi cristiana oggi, por I. De la Potterie y otros. Casale Monferrato: Piemme, 1991.

Garrido, Antonio. El texto narrativo. Madrid: Síntesis, 1996. 
Magness, J. Lee. Sense and Absence. Structure and Suspension in the Ending of Mark's Gospel. Atlanta: Scholars Press, 1986.

Marguerat, Daniel. "L'exégèse biblique à l'heure du lecteur." En La Bible en récits, editado por D. Marguerat, 13-40. Genève: Labor et Fides, 2003.

Marguerat, Daniel e Yvan Bourquin. Cómo leer los relatos bíblicos. Iniciación al análisis narrativo. Santander: Sal Terrae, 2000.

Marguerat, Daniel; André Wénin y Bernadette Escaffre. En torno a los relatos bíblicos. Estella (Navarra): Verbo Divino, 2005.

Metzger, Bruce. A Textual Commentary on the Greek New Testament. Stuttgart: German Bible Society, 1995.

Nestle, Erwin y Kurt Aland. Novum Testamentum Graece. Stuttgart: German Bible Society, 1995.

Pontificia Comisión Bíblica. La interpretación de la Biblia en la Iglesia. Madrid: PCC, 1993.

Ricoeur, Paul. "Narratividad, fenomenología y hermenéutica." Anàlisi 25 (2000): 189-207.

Shimon, Bar-Efrat. El arte de la narrativa en la Biblia. Madrid: Cristiandad, 2003.

Simian-Yofre, Horacio. (ed.). Metodologia dell'Antico Testamento. Bologna: Dehoniane, 1997.

Ska, Jean-Louis. "L'analisi narrativa." En Metodologia dell'Antico Testamento, editado por Horacio Simian-Yofre, 139-170, Bologna: Dehoniane, 1997.

Ska, Jean-Louis, J-P. Sonnet y A. Wenin. Análisis de relatos del Antiguo Testamento. Estella (Navarra): Verbo Divino, 2001.

Weren, Wim. Métodos de exégesis de los evangelios. Estella (Navarra): Verbo Divino, 2003. 